\title{
Lessons learned from the use of 1,977 in-situ bilateral internal mammary arteries: a retrospective study
}

\author{
Siamak Mohammadi ${ }^{1}$, Francois Dagenais ${ }^{1}$, Pierre Voisine ${ }^{1}$, Eric Dumont ${ }^{1}$, Richard Baillot ${ }^{1}$, Daniel Doyle ${ }^{1}$, \\ Eric Charbonneau ${ }^{1}$ and Dimitri Kalavrouziotis ${ }^{1,2^{*}}$
}

\begin{abstract}
Background: We sought to determine the early and long-term results of in-situ bilateral internal mammary artery (BIMA) grafting in patients undergoing coronary artery bypass graft surgery (CABG).

Methods: Between 1992 and 2011, 16,364 patients underwent primary isolated CABG involving at least one in-situ IMA at our institution. Among these, 1,977 patients underwent in-situ BIMA grafting: the right IMA was used to revascularize the right coronary artery system in 1,279, the circumflex system in 454 patients, and the left anterior descending (LAD) in 244. Logistic and Cox regression analyses were used to predict in-hospital mortality and cumulative late death.

Results: Late survival among BIMA patients was negatively and independently influenced by chronic obstructive pulmonary disease (hazard ratio (HR) 2.4, 95\% confidence interval (Cl) 1.6-3.4, $p=0.0005$ ), age (HR 1.2, 95\% Cl 1.1-1.3, $p<0.001$ ), and mediastinitis (HR 2.1,95\% Cl 1.1-4.2, $p<0.03$ ). Gender, body mass index, diabetes, choice of target for the second (non-LAD) IMA, and conduit grafted to the LAD (RIMA vs. LIMA) did not influence late survival among BIMA patients. A BIMA grafting strategy was significantly beneficial for younger patients. However, it was not associated with superior late survival for patients aged 66 years and above at the time of CABG, and showed a trend to harm among octogenarians (HR 1.05, 95\% Cl 0.70-1.56, $p=0.80$ ).

Conclusions: Female gender, non-insulin dependent diabetes, and the site of second IMA anastomosis did not influence early and long-term outcomes in patients undergoing CABG with in-situ BIMA grafting. The right and left IMAs are equally effective conduits for the LAD. However, advanced age, chronic obstructive pulmonary disease, and insulin-treated diabetes mellitus have a negative impact on late survival among patients with BIMA grafts.
\end{abstract}

Keywords: Coronary artery bypass graft surgery, Arterial grafts, Outcomes

\section{Background}

Given the superior late patency of the internal mammary artery (IMA) over venous grafts, it is reasonable to expect that bilateral internal mammary artery (BIMA) grafting would translate to enhanced survival following coronary artery bypass graft surgery (CABG). Numerous retrospective studies [1-3] have documented superior results associated with BIMA compared to single-IMA

\footnotetext{
* Correspondence: dimitri.kalavrouziotis@criucpq.ulaval.ca

'Division of Cardiac Surgery, Quebec Heart and Lung Institute, Quebec City, QC, Canada

${ }^{2}$ Attending surgeon, Division of Cardiac Surgery, 2725 chemin Sainte-Foy, Quebec City, QC G1V 4G5, Canada
}

\section{() BioMed Central}

(c) 2014 Mohammadi et al.; licensee BioMed Central Ltd. This is an Open Access article distributed under the terms of the Creative Commons Attribution License (http://creativecommons.org/licenses/by/4.0), which permits unrestricted use,

distribution, and reproduction in any medium, provided the original work is properly credited. The Creative Commons Public Domain Dedication waiver (http://creativecommons.org/publicdomain/zero/1.0/) applies to the data made available in this article, unless otherwise stated. grafting. However, concerns about perioperative complications and the technical challenges inherent in BIMA grafting limit its broad utilization [4]. Our institution has previously reported that there may exist an age "cutoff" after which the survival benefit associated with BIMA grafting is lost [5]. However, limited power and a relatively short follow-up restricted our ability to identify the patient subgroups that would derive maximal benefit from BIMA grafting. Therefore, the objectives of the present study were two-fold: (1) to evaluate the late survival of an expanded number of a consecutive, real-world cohort of patients with BIMA grafting with longer followup and (2) to identify which patient characteristics, if any,

artich 
make BIMA grafting prohibitive in patients undergoing CABG.

\section{Methods \\ Patients}

Clinical data were obtained from our computerized cardiac surgical database which collects information prospectively. Between January 1992 and February 2011, 16,364 consecutive adult patients underwent primary isolated CABG involving at least one in-situ IMA on the left anterior descending (LAD) at our institution. Among them, 1,977 patients with in-situ (proximally connected to the subclavian artery) BIMA grafts, with or without other supplemental venous conduits, were identified. The right IMA was used to revascularize the right coronary artery (RCA) system in 1,279 , the circumflex system in 454 , and the LAD in 244 patients. The left IMA was used to revascularize the LAD in 1,743 , the circumflex system in 181, and the diagonal in 53 patients. The choice of the coronary territory receiving the IMAs was based on coronary anatomy and surgeon preference. All patients without a provincial health insurance number as well as those who had their CABG later in the study period (after 2009) were excluded from the long-term analysis. Therefore, long-term data were available for 1,862 patients (94.2\%) with BIMA, and was $100 \%$ complete as of November 2009. The date of death was obtained from provincial vital statistics.

\section{Statistical analysis}

Results are expressed as mean \pm standard deviation (SD) or median as appropriate for continuous variables and proportions for categorical variables. Continuous and dichotomous variables were analysed using one-way ANOVA or Chisquare tests, respectively. Multivariate logistic regression was used to determine the predictors of in-hospital mortality as well as deep sternal wound infection (DSWI). KaplanMeier survival analysis was performed for late all-cause mortality and Cox proportional hazards multivariate regression modelling was used to estimate hazard ratios of late death among BIMA patients. Demographic, pre-, and intraoperative variables including territory grafted were presented to the model. Variables with a $p<0.25$ on univariate analysis were candidates for model building. The adequacy of the proportional hazards assumption was verified using the graphical representation of the logarithm of the cumulative hazard rates versus time to assess parallelism and constant separation among the different values of nominal variables; the continuous variable age was stratified into 4 disjointed strata. Also, an artificially time-dependent covariate was added to the model to test the proportionality assumption. For all variables in the final model, proportional hazards assumptions were not rejected. Statistical significance was present when the two-tailed $p$ value $<0.05$.
Analyses were performed using SAS version 9.2 (SAS Institute Inc., Cary, NC).

This study was in accordance with our institutional review board (Quebec Heart and Lung Institute Ethics Committee). Individual patient consent was waived due to the observational nature of the study.

\section{Results}

\section{Patient characteristics}

There were notable differences among BIMA and SIMA patients, with a significantly lower prevalence of several relevant risk factors in the former group (Table 1). The mean number of distal anastomoses was slightly higher among BIMA patients and aortic clamp and cardiopulmonary bypass $(\mathrm{CPB})$ times were on average approximately 6 minutes longer in the BIMA cohort. The clinical characteristics of BIMA patients were further stratified by gender, body mass index (BMI), and diabetes (Table 2). There were 243 patients with diabetes (including 50

Table 1 Baseline and operative characteristics

\begin{tabular}{|c|c|c|c|}
\hline $\begin{array}{l}\text { Variable (\% unless } \\
\text { otherwise indicated) }\end{array}$ & $\begin{array}{l}\text { BIMA } \\
n=1,977\end{array}$ & $\begin{array}{l}\text { Single IMA } \\
n=14,387\end{array}$ & $p$ value \\
\hline Age (mean years $\pm \mathrm{SD}$ ) & $55.5 \pm 8.6$ & $64.3 \pm 9.6$ & $<0.0001$ \\
\hline Female & 10.9 & 22.6 & $<0.0001$ \\
\hline Body mass index (mean $\mathrm{kg} / \mathrm{m}^{2} \pm \mathrm{SD}$ ) & $27.2 \pm 3.7$ & $27.9 \pm 4.6$ & $<0.0001$ \\
\hline Diabetes mellitus & 12.3 & 31.9 & $<0.0001$ \\
\hline Insulin-dependent & 2.5 & 9.7 & $<0.0001$ \\
\hline Renal failure & 3.4 & 7.4 & $<0.0001$ \\
\hline Previous Ml & 50.5 & 52.3 & 0.13 \\
\hline Hypertension & 49.3 & 64.0 & $<0.0001$ \\
\hline Active smoking & 32.2 & 22.0 & $<0.0001$ \\
\hline COPD & 6.2 & 13.1 & $<0.0001$ \\
\hline Peripheral vascular disease & 9.0 & 15.3 & $<0.0001$ \\
\hline Previous stroke & 3.1 & 6.3 & $<0.0001$ \\
\hline LVEF $\leq 35 \%$ & 3.9 & 6.7 & $<0.0001$ \\
\hline CHF NYHA class III or IV & 18.0 & 26.3 & $<0.0001$ \\
\hline Atrial fibrillation & 1.5 & 3.7 & $<0.0001$ \\
\hline Three-vessel disease & 58.7 & 53.0 & $<0.0001$ \\
\hline Parsonnet score (mean \pm SD) & $1.4 \pm 0.9$ & $2.1 \pm 2.2$ & $<0.0001$ \\
\hline EuroSCORE (mean $\pm \mathrm{SD})$ & $1.9 \pm 2.7$ & $3.6 \pm 4.5$ & $<0.0001$ \\
\hline \multicolumn{4}{|l|}{ Operative Data } \\
\hline Urgent or emergency & 18.5 & 23.1 & $<0.0001$ \\
\hline Off-pump & 2.3 & 3.2 & 0.03 \\
\hline Aortic clamp time (mean min \pm SD) & $57.6 \pm 18.2$ & $50.7 \pm 18.3$ & $<0.0001$ \\
\hline CPB time (mean min $\pm \mathrm{SD}$ ) & $82.4 \pm 23.8$ & $76.4 \pm 23.7$ & $<0.0001$ \\
\hline Number of distals (mean \pm SD) & $3.6 \pm 1.0$ & $3.3 \pm 1.0$ & $<0.0001$ \\
\hline
\end{tabular}


Table 2 Baseline characteristics of BIMA patients stratified by gender, body mass index, and diabetes

\begin{tabular}{|c|c|c|c|c|c|c|c|c|c|}
\hline Variable (\% unless & Male & Female & & $\mathrm{BMI}>30$ & $\mathrm{BMI} \leq \mathbf{3 0}$ & & Diabetes no insulin & No Diabetes & \\
\hline & $n=1,761$ & $n=216$ & $p$ value & $n=402$ & $n=1,575$ & $p$ value & $n=193$ & $n=1,734$ & $p$ value \\
\hline Age (mean year $\pm S D$ ) & $55.0 \pm 8.1$ & $59.2 \pm 11.5$ & $<0.0001$ & $54.3 \pm 9.3$ & $55.8 \pm 8.4$ & 0.002 & $57.4 \pm 8.7$ & $55.2 \pm 8.5$ & 0.0006 \\
\hline Female & --- & --- & --- & 11.2 & 10.9 & 0.86 & 9.3 & 10.8 & 0.62 \\
\hline $\mathrm{BMI}\left(\right.$ mean $\left.\mathrm{kg} / \mathrm{m}^{2} \pm \mathrm{SD}\right)$ & $27.3 \pm 3.7$ & $26.8 \pm 4.1$ & 0.09 & $32.6 \pm 2.3$ & $25.9 \pm 2.6$ & $<0.0001$ & $28.7 \pm 4.1$ & $27.1 \pm 3.6$ & $<0.0001$ \\
\hline Diabetes & 12.2 & 13.4 & 0.59 & 18.7 & 10.7 & $<0.0001$ & --- & --- & --- \\
\hline Insulin-dependent & 18.5 & 16.2 & 0.43 & 20.6 & 21.0 & 1.0 & --- & --- & --- \\
\hline Renal failure & 3.5 & 2.8 & 0.84 & 3.0 & 3.5 & 0.76 & 3.6 & 3.2 & 0.67 \\
\hline Previous Ml & 51.5 & 45.9 & 0.06 & 48.3 & 51.1 & 0.34 & 49.5 & 51.0 & 0.08 \\
\hline Hypertension & 59.7 & 69.0 & 0.01 & 57.7 & 47.2 & $<0.001$ & 65.8 & 68.9 & 0.15 \\
\hline Active smoking & 32.4 & 30.7 & 0.64 & 29.3 & 32.4 & 0.12 & 28.3 & 32.5 & 0.06 \\
\hline COPD & 6.4 & 4.6 & 0.37 & 6.0 & 6.3 & 0.9 & 7.3 & 6.1 & 0.53 \\
\hline Peripheral vascular disease & 8.1 & 10.2 & 0.09 & 6.5 & 9.6 & 0.05 & 11.4 & 8.0 & 0.13 \\
\hline Previous stroke & 2.9 & 5.1 & 0.09 & 3.2 & 3.1 & 0.87 & 2.6 & 3.2 & 0.83 \\
\hline LVEF $\leq 35 \%$ & 3.8 & 4.8 & 0.45 & 3.6 & 4.0 & 0.88 & 4.2 & 3.6 & 0.68 \\
\hline CHF NYHA class III or IV & 16.8 & 18.0 & 0.09 & 19.9 & 17.6 & 0.31 & 20.5 & 17.6 & 0.32 \\
\hline Atrial fibrillation & 1.5 & 1.4 & 1.00 & 2.0 & 1.4 & 3.37 & 2.1 & 1.4 & 0.56 \\
\hline Three-vessel disease & 59.2 & 54.6 & 0.21 & 59.2 & 58.6 & 0.86 & 62.7 & 58.2 & 0.25 \\
\hline
\end{tabular}

$B I M A$ bilateral internal mammary artery, CPB Cardiopulmonary bypass, CHF congestive heart failure, COPD chronic obstructive pulmonary disease, IMA internal mammary artery, LVEF left ventricular ejection fraction, MI myocardial infarction, NYHA New York Heart Association, SD standard deviation.

patients treated with insulin) among BIMA patients. Diabetic BIMA patients were on average 2 years older and had slightly higher BMI than non-diabetic BIMA patients; all other characteristics seemed to be equally distributed among diabetic and non-diabetic BIMA patients (Table 2). Among BIMA patients, there were 402 patients with a $\mathrm{BMI}>30 \mathrm{~kg} / \mathrm{m}^{2}$ (mean $32.6 \pm 2.3$ ); these patients were slightly younger than those with $\mathrm{BMI} \leq 30 \mathrm{~kg} / \mathrm{m}^{2}$ (Table 2). There were no major differences in the clinical characteristics of BIMA patients according to which IMA (right vs. left) was used to revascularize the LAD and the choice of non-LAD target receiving the second IMA (Table 3).

\section{Early outcomes}

\section{In-hospital morbidity and mortality}

The in-hospital mortality for the BIMA cohort was 1.0\% $(\mathrm{n}=20)$ compared with $1.8 \%(\mathrm{n}=264)$ among the single IMA patients $(p=0.009)$ (Table 4$)$. The multivariate predictors of in-hospital mortality among the entire cohort of CABG patients with at least one in-situ IMA on the LAD were: age $>75$ years (odds ratio (OR) 2.5, 95\% confidence interval (CI) $1.8-3.4, p<0.0001$ ), female gender (OR 1.9, 95\% CI 1.4-2.5, $p<0.0001$ ), preoperative renal failure (OR 3.1, 95\% CI 2.2-4.3, $p<0.0001$ ), postoperative stroke (OR 4.3, 95\% CI 2.7-6.8, $p<0.0001$ ), postoperative de-novo renal failure (OR 3.1, 95\% CI 2.2-4.2, $p<0.0001$ ), mechanical ventilation $>48$ hours (OR 11.2, 95\% CI 8.0-15.6, $p<0.0001$ ), and duration of CPB (OR $1.1,95 \%$ CI 1.01-1.2, $p<0.0001)$. BIMA was not associated with in-hospital mortality on multivariate analysis $(p=0.43)$. Among BIMA patients, the site of the second IMA anastomosis to a non-LAD target ( $p=$ 0.33 ), the use of the left versus right IMA to revascularize the LAD $(p=0.25)$, female gender $(p=0.47)$, and DSWI $(p=0.39)$ were not associated with in-hospital mortality on univariate logistic regression.

\section{Deep sternal wound infection}

The incidence of DSWI was doubled in the BIMA patients $(2.4 \%(\mathrm{n}=48)$ vs. $1.2 \%(\mathrm{n}=172), p<0.0001)$ (Table 4$)$. Diabetes was more prevalent among patients who developed DSWI compared to those who did not have this complication (37.5\% vs. $11.7 \%, p<0.0001)$. Mean age $(58.2 \pm 8.1$ vs. $55.4 \pm 8.6, p=0.02)$, mean BMI (29.8 \pm 4.3 vs. $27.2 \pm 3.7, p<$ $0.0001)$, mean Parsonnet score $(8.0 \pm 5.9$ vs. $4.9 \pm 4.9, p<$ $0.0001)$ and the prevalence of chronic obstructive pulmonary disease (COPD) $(14.6 \%$ vs. $6.0 \%, p=0.02)$, peripheral vascular disease $(20.8 \%$ vs. $8.7 \%, p=0.01)$, and female gender $(20.8 \%$ vs. $10.7 \%, p=0.03$ ) were higher among BIMA patients who developed DSWI compared to those who did not. The multivariate independent predictors of DSWI in the entire cohort are shown in Table 5. In this model, no statistically significant effect modification was identified between BIMA and the other predictors of DSWI.

\section{Long-term survival}

The median follow-up of BIMA patients was 8.1 years (interquartile range, 4.7 to 13 years). During follow-up, 
Table 3 Baseline characteristics of BIMA patients stratified by use of left versus right IMA to revascularize the LAD (left part of table), and by choice of non-LAD target (RCA vs. circumflex) for the second IMA (right part of table)

\begin{tabular}{|c|c|c|c|c|c|c|}
\hline $\begin{array}{l}\text { Variable (\% unless } \\
\text { otherwise indicated) }\end{array}$ & $\begin{array}{l}\text { RIMA-LAD } \\
\mathrm{n}=234\end{array}$ & $\begin{array}{l}\text { LIMA-LAD } \\
n=1,743\end{array}$ & $p$ value & $\begin{array}{l}\text { 2nd IMA-Cx } \\
\mathrm{n}=650\end{array}$ & $\begin{array}{l}\text { 2nd IMA-RCA } \\
n=1,239\end{array}$ & $p$ value \\
\hline Age (mean years $\pm S D$ ) & $54.1 \pm 8.7$ & $55.6 \pm 8.5$ & 0.06 & $55.8 \pm 8.4$ & $55.4 \pm 8.5$ & 0.31 \\
\hline Female & 10.8 & 11.0 & 0.9 & 10.7 & 11.1 & 0.88 \\
\hline BMI (mean kg/m² $\pm S D$ ) & $27.3 \pm 3.8$ & $27.1 \pm 3.7$ & 0.83 & $27.3 \pm 3.8$ & $27.2 \pm 3.6$ & 0.65 \\
\hline Diabetes mellitus & 13.8 & 12.2 & 0.49 & 13.7 & 12.5 & 0.52 \\
\hline Insulin-dependent & 18.5 & 21.5 & 1.0 & 18.7 & 22.9 & 0.51 \\
\hline Renal failure & 5.1 & 3.2 & 0.15 & 2.1 & 3.0 & 0.07 \\
\hline Previous Ml & 45.9 & 51.0 & 0.2 & 43.7 & 47.8 & 0.24 \\
\hline Hypertension & 44.9 & 50.1 & 0.18 & 55.2 & 56.1 & 0.19 \\
\hline Active smoking & 33.2 & 32.0 & 0.74 & 30.4 & 33.0 & 0.29 \\
\hline COPD & 5.6 & 6.2 & 0.88 & 6.7 & 5.6 & 0.46 \\
\hline Peripheral vascular disease & 8.2 & 8.9 & 0.79 & 9.9 & 8.5 & 0.34 \\
\hline Previous stroke & 2.0 & 3.3 & 0.39 & 2.3 & 3.6 & 0.13 \\
\hline LVEF $\leq 35 \%$ & 3.6 & 3.9 & 1.0 & 4.8 & 3.4 & 0.15 \\
\hline CHF NYHA class III or IV & 19.5 & 18.0 & 0.62 & 15.5 & 17.3 & 0.55 \\
\hline Atrial fibrillation & 2.6 & 1.4 & 0.22 & 1.5 & 1.3 & 0.83 \\
\hline Three-vessel disease & 56.1 & 58.9 & 0.44 & 56.8 & 64.9 & 0.08 \\
\hline Parsonnet score (mean \pm SD) & $1.3 \pm 0.9$ & $1.4 \pm 0.9$ & 0.76 & $1.4 \pm 1.0$ & $1.3 \pm 0.9$ & 0.12 \\
\hline EuroSCORE (mean \pm SD) & $1.6 \pm 1.4$ & $1.9 \pm 2.8$ & 0.06 & $2.0 \pm 2.9$ & $1.9 \pm 2.6$ & 0.44 \\
\hline
\end{tabular}

BIMA bilateral internal mammary artery, CPB Cardiopulmonary bypass, CHF congestive heart failure, COPD chronic obstructive pulmonary disease, IMA internal mammary artery, LVEF left ventricular ejection fraction, MI myocardial infarction, NYHA New York Heart Association, SD standard deviation.

there were a total of 208 deaths in the cohort of patients with BIMA. BIMA patients with diabetes had significantly lower unadjusted survival rates $(91.7 \%, 84.4 \%$ and $77.0 \%)$ compared to BIMA patients without diabetes at 5,10 , and 15 years $(96.0 \%, 89.8 \%$ and $81.5 \%$, log-rank $p=0.006)$. However, once insulin-dependent diabetics were removed from this analysis, there was no longer a survival disparity between BIMA patients without diabetes and those with non-insulin dependent diabetes

Table 4 Postoperative adverse events

\begin{tabular}{llll}
\hline $\begin{array}{l}\text { Outcome (\% unless otherwise } \\
\text { indicated) }\end{array}$ & BIMA & Single IMA & \\
\hline Mortality & $\mathbf{n = 1 , 9 7 7}$ & $\mathbf{n = 1 4 , 3 8 7}$ & $\boldsymbol{p}$ value \\
De-novo atrial fibrillation & 15.6 & 1.8 & 0.009 \\
Re-exploration for bleeding & 3.7 & 3.7 & $<0.0001$ \\
De-novo renal failure* & 3.9 & 7.0 & 0.96 \\
Stroke & 0.8 & 1.7 & $<0.0001$ \\
Deep sternal wound infection & 2.4 & 1.2 & 0.003 \\
Mechanical ventilation $>$ 48 hours & 1.8 & 2.8 & $<0.0001$ \\
Blood product transfusion & 42.2 & 48.5 & 0.01 \\
Mean hospital length of stay (days) & 5 & 6 & 0.01 \\
\hline
\end{tabular}

${ }^{*}$ Defined as a $50-\mu \mathrm{mol} / \mathrm{L}$ absolute rise in baseline serum creatinine or a new need for dialysis.

BIMA bilateral internal mammary arteries. (log-rank $p=0.28$, Figure 1A). BIMA patients with DSWI had lower 5-, 10-, and 15-year survival (85.6\%, $77.6 \%$ and $69.8 \%$ ) compared to BIMA patients without this type of infection $(95.8 \%, 89.4 \%$ and $81.2 \%$, logrank $p=0.0009$, Figure $1 \mathrm{~B})$. There were no significant late survival differences among BIMA patients stratified by BMI $(\log$-rank $p=0.53)$ and gender $(\log$-rank $p=0.08)$ (Figure 1C, D).

When we looked at the non-LAD target of the second IMA, unadjusted survival rates at 5, 10, and 15 years were $95.6 \%, 89.0 \%$ and $80.9 \%$ for patients with a second IMA anastomosis to the RCA system, which was not significantly different compared to those in whom the second IMA was anastomosed to the circumflex system (96.0\%, 92.1\% and 84.0\%, log-rank $p=0.2$, Figure 2A). Furthermore, using the left versus the right IMA to revascularize the LAD had no impact on late survival, although there was a trend toward better survival among those patients who received LIMA to the LAD (log-rank $p=0.06$, Figure 2B).

The Cox multivariate proportional hazards model identified age, COPD, and DSWI as the independent predictors of late death among BIMA patients (hazard ratio (HR) 1.2, 95\% CI 1.1-1.3, $p<0.001$; HR 2.4, 95\% CI 1.6$3.4, p=0.0005$; and HR 2.1, 95\% CI 1.1-4.2, $p<0.03$, respectively). The site of the second (non-LAD) IMA 
Table 5 Multivariate predictors of deep sternal wound infection

\begin{tabular}{llll}
\hline Variable & Odds ratio & $\mathbf{9 5 \% ~ C l}$ & $\boldsymbol{p}$ value \\
\hline BIMA & 3.8 & $2.6-5.4$ & $<0.0001$ \\
Diabetes mellitus & 2.2 & $1.6-2.9$ & $<0.0001$ \\
COPD & 2.2 & $1.6-3.1$ & $<0.0001$ \\
Preoperative dialysis-dependent & 3.1 & $1.3-7.9$ & 0.01 \\
renal failure & & & \\
Postoperative delirium & 1.6 & $1.04-2.4$ & 0.03 \\
Postoperative renal failure* $^{*}$ & 2.2 & $1.5-3.2$ & $<0.0001$ \\
Reexploration for bleeding & 2.6 & $1.6-4.2$ & $<0.0001$ \\
${\text { Mechanical ventilation }>48 \text { hours }^{\dagger}}$ & 4.6 & $3.0-7.0$ & $<0.0001$ \\
Body mass index $^{\dagger}$ & 1.12 & $1.1-1.2$ & $<0.0001$ \\
Left ventricular ejection fraction $^{\dagger}$ & 0.9 & $0.8-0.92$ & $<0.0001$ \\
\hline
\end{tabular}

*Defined as a $50-\mu \mathrm{mol} / \mathrm{L}$ absolute rise in baseline serum creatinine or a new need for dialysis.

${ }^{\dagger}$ Submitted to the model as continuous variables.

$\mathrm{Cl}$ confidence interval, $C P B$ cardiopulmonary bypass. anastomosis, the use of a sequential technique, the use of the right versus the left IMA to bypass the LAD, female gender, BMI, and non-insulin dependent diabetes were not associated with long-term mortality among BIMA patients in this model. Analysis stratified by age shows that survival benefit is lost after 65 years of age, and that there may be a survival detriment associated with BIMA at age 80 (Table 6).

\section{Discussion}

Several findings in this study are worthy of note. First, a very low operative mortality (1\%) was observed in this contemporary, real-world cohort of BIMA patients. These data are consistent with a recent randomized trial examining BIMA vs. single IMA which reported a 30day mortality of $1.2 \%$ [6]. Second, the choice of target for the second (non-LAD) IMA did not influence late survival. Previous reports had suggested that the patency of the right IMA may be lower if placed to the RCA territory due to size discrepancy and competitive flow $[7,8]$. More recent data from the Cleveland Clinic group [9] and others [10] have shown that the right IMA could be placed to left-sided coronaries or, alternatively, RCA

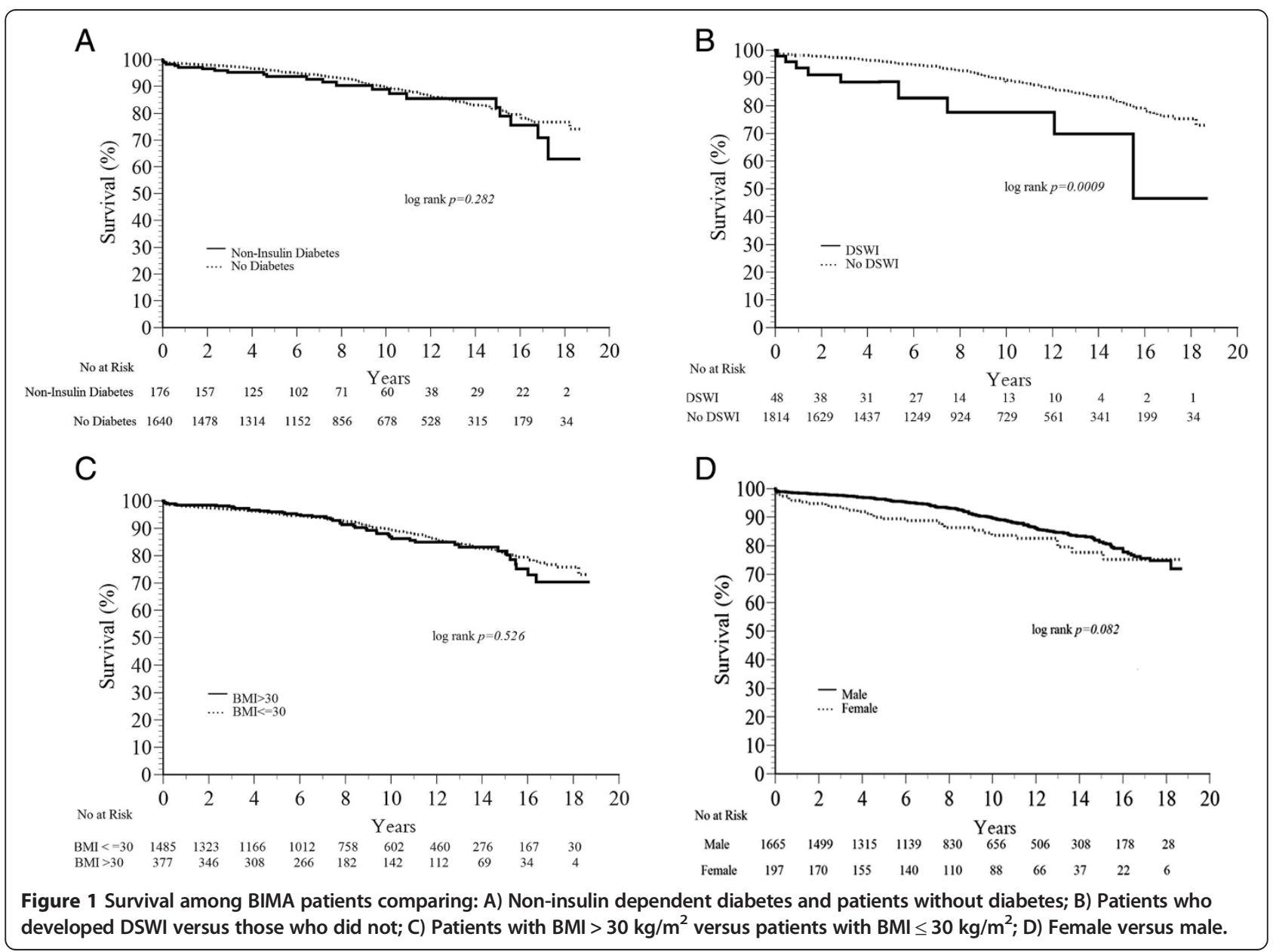




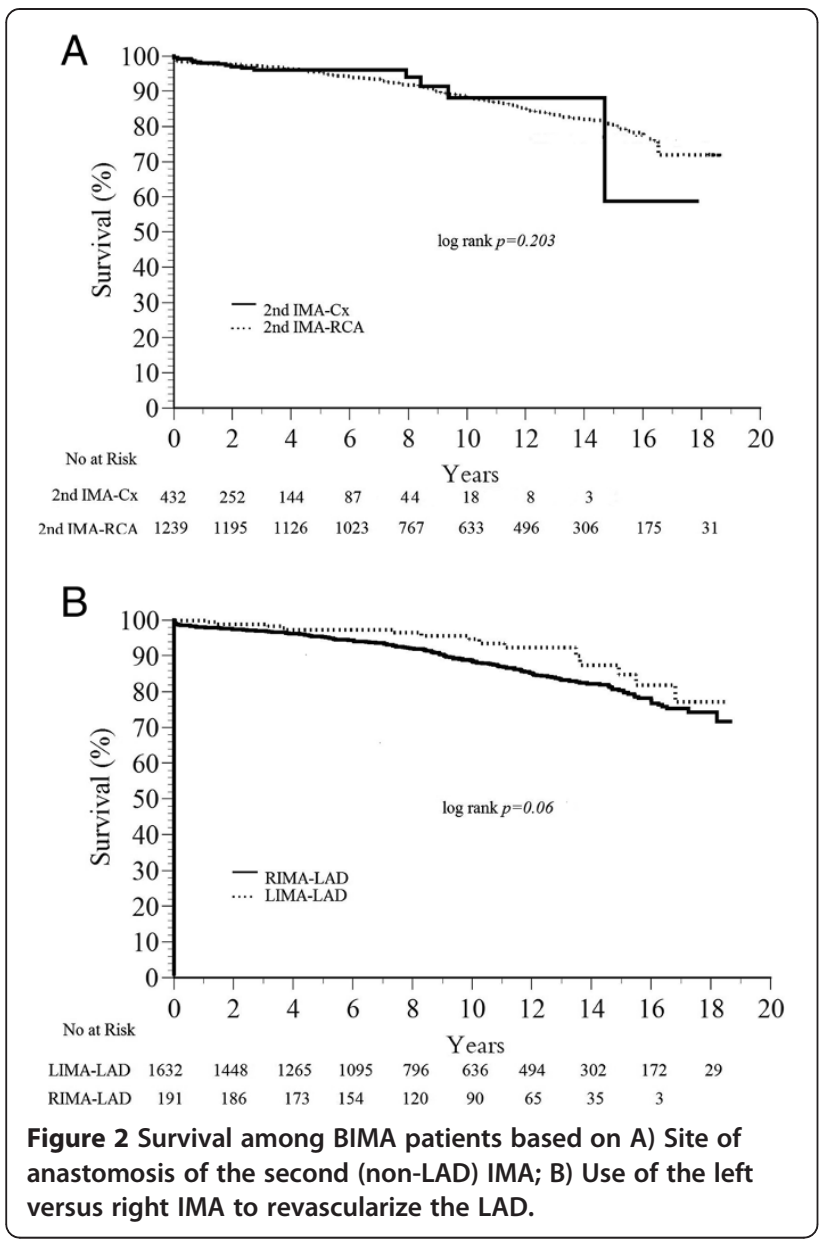

Table 6 Hazard ratios of late mortality according to age among BIMA patients

\begin{tabular}{lll}
\hline Age (years) & Hazard Ratio $(\mathbf{9 5} \% \mathrm{Cl})$ & $\boldsymbol{P}$-value \\
\hline 50 & $0.64(0.51-0.82)$ & 0.0003 \\
55 & $0.70(0.58-0.84)$ & 0.0001 \\
60 & $0.76(0.65-0.89)$ & 0.0007 \\
65 & $0.82(0.68-0.99)$ & 0.0412 \\
66 & $0.83(0.69-1.01)$ & 0.0759 \\
67 & $0.85(0.6-1.04)$ & 0.1272 \\
68 & $0.86(0.6-1.07)$ & 0.1953 \\
69 & $0.88(0.70-1.10)$ & 0.2779 \\
70 & $0.89(0.70-1.14)$ & 0.3711 \\
75 & $0.97(0.70-1.56)$ & 0.8550 \\
80 & $1.05(0.70-1.56)$ & 0.7978 \\
\hline
\end{tabular}

For clarity, age categories are shown at 5-year intervals except between the ages of 65 and 70 where they are shown per annum, in order to determine the age between 65 and 70 years at which the benefit of BIMA is no longer statistically significant. This occurs at 66 years of age. territory targets with similar early and late outcomes. Although we observed a trend to an improved unadjusted survival among BIMA patients in which the LIMA was grafted to the LAD compared to those in which the RIMA was grafted to the LAD (log-rank $p=0.06$, Figure $2 \mathrm{~B}$ ), this factor was not predictive of late survival in the Cox multivariate model.

Another relevant finding from our data is that the use of insulin was the major driver behind the survival disadvantage of diabetes in patients undergoing BIMA, such that there was no difference in survival among diabetics who were not receiving chronic outpatient insulin therapy and those without diabetes (Figure 1A). Looking at the data from Table 2, we see that there a very few clinically relevant differences between the patients with diabetes not treated with insulin receiving BIMA and those without diabetes receiving BIMA which may explain the equivalent survival outcome. The contribution of diabetes to adverse events and mortality following BIMA grafting remains controversial with conflicting results in the literature [11-14]. However, our data suggest that diabetes in the absence of insulin therapy should not deter a surgeon from pursuing a BIMA revascularization strategy.

The fear of sternal devascularisation and infection is a major limitation in the widespread use of BIMA. However, recent advances in the management of DSWI have lessened its impact on CABG outcomes [13]. The role of diabetes as a major risk factor for DSWI has been extensively studied. The prevalence of diabetes was three times higher among patients with DSWI versus those without DSWI in our series which is consistent with observations in the Arterial Revascularisation Trial (ART) [6]. In an earlier report, Cosgrove et al. [14] studied the risk of BIMA grafting and identified diabetes and advanced age, but not BIMA grafting itself, as risk factors for wound complications. Although the incidence of DSWI after BIMA grafting is relatively low in most series, the morbidity and cost associated with sternal infection are significant $[12,15]$. This increase in the risk of sternal infection in diabetic patients has to be balanced against the fact that diabetic patients may actually have the most to gain from BIMA grafting [16,17]. Our data show that, excluding diabetics treated with insulin, diabetic BIMA patients had a significantly better survival compared to single IMA patients. The presence of endorgan compromise related to diabetes, associated risk factors, and IMA harvesting technique should be taken into consideration for surgical decision-making [18]. The risk of DSWI may be minimized with careful patient selection and modification of the IMA harvesting technique, particularly in diabetic patients. Furthermore, in our study, diabetes was not an independent predictor of late death after BIMA grafting. A recent report by our 
group [19] has also shown that long-term survival after CABG was not adversely affected by the presence of non-insulin-dependent diabetes. These findings suggest that long-term survival of diabetic patients after CABG may be mainly related to the presence of diabetes comorbidities, namely peripheral vascular disease, renal failure, low ejection fraction, and insulin dependency. Stevens et al. [17] have shown that BIMA use in diabetic patients improves survival and decreases the risk of coronary reoperation compared with single IMA grafting.

Another finding worthy of note is that female gender, patients with high BMI, and history of smoking did not negatively influence long-term survival after BIMA grafting in our study. The finding of a lack of association between BMI and survival according to grafting strategy may reflect a lack of sufficient power in our study to detect a difference, given the fact that BMI was extremely similar among the 2 groups (Table 1 ) and very obese patients $(\mathrm{BMI}>40)$ were conspicuously absent from the BIMA group. Earlier studies have shown that female gender is an independent risk factor for in-hospital and long-term mortality after CABG. It has been also suggested that women derive less benefit from BIMA grafting. However, recent reports $[20,21]$ have not validated these data, and women appear to benefit from BIMA grafting as much as men.

\section{Limitations}

This study has some inherent limitations. It was performed in a non-randomized manner in a single referral center. Also, our analysis does not account for the timedependent nature of certain patient characteristics, such as ejection fraction and diabetes, which are prognostically important and may change over time. The prevention of graft disease has evolved with the introduction of new drug therapies during follow-up, but we expect these new treatments to have been equally distributed among the groups we studied. Our data suggest that the late survival benefit appears to be lost after the age of 65 for patients undergoing BIMA grafts. It is not unreasonable to expect that these patients may continue to experience sustained improvements in anginal status and quality of life owing to better long-term patency of arterial grafts; however, these variables were not specifically assessed in this study. We excluded free IMA grafts and alternative arterial conduits such as the radial artery from our analysis in order to increase the homogeneity of the studied patients and allow for meaningful multivariate analyses within this patient subgroup.

\section{Conclusion}

An in-situ BIMA grafting strategy should not be withheld from patients according to sex, BMI, and from those with diabetes mellitus. However, advanced age,
COPD, and patients with insulin-treated diabetes mellitus may not benefit from BIMA grafts. The right and left IMAs are equally effective conduits for the LAD, and the non-LAD coronary artery territory grafted by the second IMA did not influence outcome.

\section{Abbreviations}

CABG: Coronary artery bypass graft surgery; Cl: Confidence interval;

COPD: Chronic obstructive pulmonary disease; CPB: Cardiopulmonary bypass; BIMA: Bilateral internal mammary arteries; BMI: Body mass index; DSWI: Deep sternal wound infection; HR: Hazard ratio; IMA: Internal mammary artery; LAD: Left anterior descending artery; LIMA: Left internal mammary artery; OR: Odds ratio; RCA: Right coronary artery; SD: Standard deviation.

\section{Competing interests}

The authors declare that they have no competing interests.

\section{Authors' contributions}

SM conceived of the study, participated in its design and coordination, and wrote the first draft of the manuscript. FD and PV participated in study design and coordination, data collection, and in revising the manuscript for important content. ED, RB, DD, and EC participated in data collection and in revising the manuscript for important content. DK participated in study design, the analysis and interpretation of data, and in writing the final version of the manuscript. All authors have read and approved the final manuscript and take full responsibility for its content.

\section{Acknowledgements}

The authors would like to thank Stephanie Dionne, Emilie Dallaire, and Serge Simard for their assistance in collection of the data and statistical analysis.

Received: 20 May 2014 Accepted: 2 September 2014

Published online: 20 September 2014

\section{References}

1. Galbut DL, Traad EA, Dorman MJ, DeWitt PL, Larsen PB, Kurlansky PA, Carrillo RG, Gentsch TO, Ebra G: Coronary artery bypass grafting in the elderly: single versus bilateral internal mammary artery grafts. J Thorac Cardiovasc Surg 1993, 106:128-135.

2. Lytle BW, Blackstone EH, Sabik JF, Houghtaling P, Loop FD, Cosgrove DM: The effect of bilateral internal thoracic artery grafting on survival during 20 postoperative years. Ann Thorac Surg 2004, 78:2005-2012.

3. Lytle BW, Blackstone EH, Loop FD, Houghtaling PL, Arnold JH, Akhrass R, McCarthy PM, Cosgrove DM: Two internal thoracic artery grafts are better than one. J Thorac Cardiovasc Surg 1999, 117:855-872.

4. Tabata M, Grab JD, Khalpey Z, Edwards FH, O'Brien SM, Cohn LH, Bolman RM 3rd: Prevalence and variability of internal mammary artery graft use in contemporary multivessel coronary artery bypass graft surgery: analysis of the society of thoracic surgeons national cardiac database. Circulation 2009, 120:935-940.

5. Mohammadi S, Dagenais F, Doyle D, Mathieu P, Baillot R, Charbonneau E, Perron J, Voisine P: Age cut-off for the loss of benefit from bilateral internal thoracic artery grafting. Eur J Cardiothorac Surg 2008, 33:977-982.

6. Taggart DP, Altman DG, Gray AM, Lees B, Nugara F, Yu LM, Campbell H, Flather M, ART Investigators: Randomized trial to compare bilateral vs. Single internal mammary coronary artery bypass grafting: 1-year results of the arterial revascularisation trial (ART). Eur Heart J 2010, 31:2470-2481.

7. Taggart DP, D'Amico R, Altman DG: The effect of arterial revascularisation on survival: a systematic review of studies comparing bilateral and single internal mammary arteries. Lancet 2001, 358:870-875.

8. Schmidt SE, Jones JW, Thornby Jl, Miller CC, Beall AC: Improved survival with multiple left-sided bilateral internal thoracic artery grafts. Ann Thorac Surg 1997, 64:9-14.

9. Sabik JF 3rd, Stockins A, Nowicki ER, Blackstone EH, Houghtaling PL, Lytle BW, Loop FD: Does location of the second internal thoracic artery graft influence outcome of coronary artery bypass grafting? Circulation 2008, 118(Suppl 14):S210-S215.

10. Kurlansky PA, Traad EA, Dorman MJ, Galbut DL, Zucker M, Ebra G: Location of the second internal mammary artery graft does not influence 
outcome of coronary artery bypass grafting. Ann Thorac Surg 2011, 91:1378-1382.

11. Grau JB, Ferrari G, Mak AW, Shaw RE, Brizzio ME, Mindich BP, Strobeck J, Zapolanski A: Propensity matched analysis of bilateral internal mammary artery versus single left internal mammary artery grafting at 17-year follow-up: validation of a contemporary surgical experience. Eur J Cardiothorac Surg 2012, 41:770-775.

12. Loop FD, Lytle BW, Cosgrove DM, Mahfood S, McHenry MC, Goormastic M, Stewart RW, Golding LA, Taylor PC: J. Maxwell Chamberlain memorial paper: sternal wound complications after isolated coronary artery bypass grafting: early and late mortality, morbidity, and cost of care. Ann Thorac Surg 1990, 49:179-186.

13. Baillot R, Cloutier D, Montalin L, Cote L, Lellouche F, Houde C, Gaudreau G, Voisine $P$ : Impact of deep sternal wound infection management with vacuum-assisted closure therapy followed by sternal osteosynthesis: a 15-year review of 23,499 sternotomies. Eur J Cardiothorac Surg 2010, 37:880-887.

14. Cosgrove DM, Lytle BW, Loop FD, Taylor PC, Stewart RW, Gill CC, Golding LA, Goormastic M: Does bilateral internal mammary artery grafting increase surgical risk? J Thorac Cardiovasc Surg 1988, 95:850-856.

15. Toumpoulis IK, Anagnostopoulos CE, Derose J Jr, Swistel DG: The impact of deep sternal wound infection on long-term survival after coronary artery bypass grafting. Chest 2005, 127:464-471.

16. Lawlor DA, Adamson J, Ebrahim S: Seven-year outcome in the bypass angioplasty revascularization investigation (BARI) by treatment and diabetic status. J Am Coll Cardiol 2000, 35:1122-1129.

17. Stevens LM, Carrier M, Perrault LP, Hebert Y, Cartier R, Bouchard D, Fortier A, Pellerin M: Influence of diabetes and bilateral internal thoracic artery grafts on long-term outcome for multivessel coronary artery bypass grafting. Eur J Cardiothorac Surg 2005, 27:281-288.

18. Boodhwani M, Lam BK, Nathan HJ, Mesana TG, Ruel M, Zeng W, Sellke FW, Rubens FD: Skeletonized internal thoracic artery harvest reduces pain and dysesthesia and improves sternal perfusion after coronary artery bypass surgery: a randomised, double-blind, within-patient comparison. Circulation 2006, 114:766-773.

19. Mohammadi S, Dagenais F, Mathieu P, Kingma JG, Doyle D, Lopez S, Baillot R, Perron J, Charbonneau E, Dumont E, Metras J, Desaulniers D, Voisine P: Long-term impact of diabetes and its comorbidities in patients undergoing isolated primary coronary artery bypass graft surgery. Circulation 2007, 116(Suppl 11):1220-I225.

20. Saxena A, Poh CL, Dinh DT, Reid CM, Smith JA, Shardey GC, Newcomb AE: Does patient gender affect outcomes after concomitant coronary artery bypass graft and aortic valve replacement? An Australian society of cardiac and thoracic surgeons database study. Cardiology 2011, 119:116-123.

21. Kurlansky PA, Traad EA, Dorman MJ, Galbut DL, Zucker M, Ebra G: Thirty-year follow-up defines survival benefit for second internal mammary artery in propensity-matched groups. Ann Thorac Surg 2010, 90:101-108.

doi:10.1186/s13019-014-0158-9

Cite this article as: Mohammadi et al:: Lessons learned from the use of 1,977 in-situ bilateral internal mammary arteries: a retrospective study. Journal of Cardiothoracic Surgery 2014 9:158.

\section{Submit your next manuscript to BioMed Central and take full advantage of:}

- Convenient online submission

- Thorough peer review

- No space constraints or color figure charges

- Immediate publication on acceptance

- Inclusion in PubMed, CAS, Scopus and Google Scholar

- Research which is freely available for redistribution

Submit your manuscript at www.biomedcentral.com/submit
Ciomed Central 